thermostatic control is fitted. Presumably a baby suffering from artificial heat-stroke would have the symptoms of dehydration fever, and the cause of death would be " prematurity." Too great a weight of blankets on the infant's cot may possibly be a cause of fatigue of the respiratory muscles-and death. The zealous, harassed, but inexperienced mother should be warned of this risk. Is the danger fully realized ?

Though, as already stated, I have not yet seen in print any expression of approval of my suggestion to have this matter thoroughly and conscientiously investigated, obstetric specialists in centres in this country and as far afield as Australia have expressed their complete agreement with my remarks. The surprise and disappointment of 'being ostracized on account of these letters by some with whom I had worked most happily for many years have been compensated by the (to me) unknown "feckless," anaemic, and frail little woman living under slum conditions, who had seen an extract of my letter in the lay Press, telling me that she had had no further trouble with her ailing baby after heeding the suggestion and abandoning the tight wrapping she had been taught.

Much of this may seem irrelevant as far as Dr. Lewis's article is concerned, but as the object of all of us is to save these precious lives I appeal once more to all doctors and nurses to satisfy themselves beyond all doubt that the infants under their care are not being slowly suffocated in the way described.I am, etc.,

Huddersfield.

S. H. WADDY.

\section{Periarteritis Nodosa}

SIR,-I was interested in Dr. L. M. Shorvon's case of periarteritis nodosa (May 3, p. 601). The difficulty of making this diagnosis during life lies in the diversity and the frequently changing character of the physical signs and symptoms in this condition. But it is just the great variety of the clinical picture e.g., fever of the remittent type, tachycardia, polyneuritis, polymyositis, albuminuria and cylindruria, asthmatic attacks with bronchitis, hypertension, and leucocytosis with blood-eosinophilia-which is suggestive of periarteritis nodosa. The conception of periarteritis nodosa being the result of an extreme degree of vascular allergy has found wide recognition in recent years. It therefore seems doubtful whether this condition represents a disease entity but rather belongs to the wider group of diseases caused by the anaphylactic hyperergic reactions-e.g., Loeffler's syndrome, angioneurotic oedema, tropical eosinophilia, and probably rhemmatic fever. The principal difference of these conditions lies in the intensity and extent of the vascular involvement. In a recent publication of two cases of periarteritis nodosa (A. Elkeles and L. E. Glynn, Brit. J. Radiol., 1944, 17, 368) we showed in serial radiographs of the chest the occurrence of transitory infiltrations in the lungs during the early stages of the disease. These were later superseded by persistent and progressive damage to the pulmonary vessels and bilateral pleural effusion. The presence of transitory as well as persistent and progressive changes in the lungs, with concomitant blood eosinophilia and the severe clinical picture, made a correct diagnosis possible during life. Transitory pulmonary infiltrations and blood eosinophilia are also met with in Loeffler's syndrome ; but here the clinical picture is characterized by a mild course, and the lung infiltrations usually disappear completely within a few days, although in rare instances migratory pulmonary lesions may persist for several months.

In contrast to the striking radiological findings, physical signs of the lungs in Dr. Shorvon's case and in our cases were scanty and even absent. That is why little attention has been paid so far to the pulmonary changes in this condition, which, however, as shown by serial $x$-ray examination, may provide an important clue to this notoriously difficult disease.-I am, etc.,

London, W.1.

A. Elkeles.

\section{Heroin and Pethidine during Labour}

SIR,-I would like to express appreciation of the scholarly paper by Miss Josephine Barnes (April 5, p. 437) on the use of pethidine in labour. Pethidine is certainly a safe drug to use and has many advantages. It has one very serious disadvantage, however, and that is that its action is unreliable. In Miss Barnes's series good analgesia was obtained in only $55 \%$ of cases, a figure in accord with my own much smaller experience of pethidine.

There is one drug, however, which is vastly superior to pethidine, and that drug is heroin (diamorphine hydrochloride). In analgesic effect heroin is much more powerful than pethidine, and its action is very much more reliable. When properly used it does not interfere with the normal course of labour and, as I have already shown in a previous communication (Jan. 8, 1944 , p. 59), it can be safely given in full doses at any time during labour.

With experience one varies the dose according to the type and frequency of the contractions and the degree of dilatation of the cervix, but as a general guide one would say that $1 / 6 \mathrm{gr}$. $(10.8 \mathrm{mg}$.) should be given when the cervix is three fingers dilated and a further $1 / 12$ or. $(5.4 \mathrm{mg})_{\text {i }}$ just before full dilatation. If the cervix is almost fully dilated or the second stage has already commenced when first seen one would give the full dose of $1 / 6 \mathrm{gr}$. $(10.8 \mathrm{mg}$.) straight away. It is important not to give heroin too soon in the first stage, or else uterine action will be damped down. In this respect heroin differs from pethidine, which can be given earlier in labour. In those cases where the contractions are weak and some degree of uterine inertia is present I prefer to give pethidine rather than heroin.

When heroin is given in adequate doses, supplementary anaesthesia at the end of the second stage is not always required. When it is deemed necessary, a little chloroform or gas and air can be administered. For certain cases, particularly breech delivery, I find pudendal block very efficacious.

There are of course other aspects of the prevention and relief of pain in labour apart from the administration of analgesic drugs, and it is important not to neglect them. For example, there is the overcoming of fear and tension, and there are those measures designed to promote flexibility of the pelvic joints during pregnancy. The actual method which one employs to relieve pain in labour is probably of secondary importance. What is far more important is that everyone should master some method and apply it conscientiously. There is, unfortunately, far too much apathy and indifference among those who undertake maternity work. To make no attempt to relieve pain in labour, or to make only a half-hearted attempt, is a sign of slackness and a public confession of mediocrity.-I am, etc.,

Troon, Ayrshire.

JAMES RosS.

\section{Artificial Insemination}

SIR,-In the answer to a correspondent's inquiry about the technique of artifical insemination ("Any Questions," May 3, p. 625) you conclude: "Finally, attention should be drawn to the medico-legal aspects of this procedure," and refer him to a leading article on the subject in the same issue. While conceding that the leading article was intended to cover only a special aspect of the subject, I feel strongly that the answer should have included an admonition about the psychological as well as the medico-legal aspects. As your leading article points out, the legal status of the procedure and its consequences are still beset by doubts, but even a lay person unacquainted with formal psychology can hardly doubt that serious psychological dangers threaten all those who accept artificial insemination.

It is the clear duty of doctors and psychologists to point out the formidable hazards to happiness and peace of mind which confront all who resort to this expedient. The vital human factors, which should outweigh all other considerations, have received a minimum of attention or have been ignored as matters of small moment compared with the technical problems involved.

It is a fact that couples who request artificial insemination constitute a cross-section of psychological types. It is, moreover, by no means easy for even an expert psychologist to predict with confidence that any couple will not eventually experience strong emotional reactions which may become increasingly intense as the years pass. The manifold and ineradicable psychological difficulties which might wreck the lives of the woman who accepts A.I.D., her husband, and the "testtube" child will be evident to anyone who gives the subject a moment's thought. However eagerly she may have resorted to the method in her desire for a child, the woman sooner or later is likely to experience a vague feeling of dissatisfaction with herself-what we might almost term a sense of sin, af 